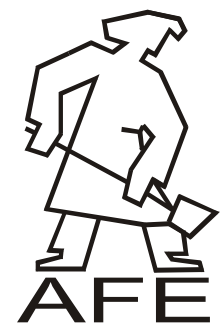

FOUNDRY ENGINEERING

DOI: 10.2478/afe-2013-0080
ISSN (2299-2944)

Volume 13

Issue $4 / 2013$

$49-52$

\title{
Evaluation Criteria of Wax Pattern Strength Tests and their Role in Forecasting the Shape Accuracy of Wax Patterns
}

\author{
R. Haratym ${ }^{\text {a }}$, R. Biernacki ${ }^{\text {b* }}$, J. Lewiński ${ }^{\text {a }}$, J. Kwapisz ${ }^{\text {c }}$ \\ ${ }^{a}$ University of Ecology and Management, Wawelska 14, 02-061 Warsaw, Poland \\ ${ }^{\mathrm{b}}$ Warsaw University of Technology, Institute of Manufacturing Technologies, Narbutta 85, 02-524 Warsaw, Poland \\ ${ }^{\mathrm{c}}$ Instituto Superior Tecnico, MIT Portugal, Av. Rovisco Pais, 1, 1049-001 Lisboa, Portugal \\ *Corresponding author. E-mail address: r.biernacki@wip.pw.edu.pl
}

Received 29.06.2013; accepted in revised form 02.09.2013

\begin{abstract}
This research paper will present and analyze selected testing of wax patterns - bending strength test, test of resistance to creep and penetration hardness test. Evaluation of these tests will be carried out in terms of the shape accuracy of wax patterns.

Additionally, statistical evaluation will be carried out of relationships between selected parameters of previously mentioned tests. Standard bending tests will be statistically evaluated and compared with two other test methods conducted on corresponding patterns.

Particular attention will be given to creep resistance, which is a very useful test method for assessing changes in the shape of complex patterns in the function of time and temperature.

At the same time an evaluation of hardness tests of wax patterns will be carried out with usage of appropriate samples or by direct examination of the production patterns.
\end{abstract}

Keywords: Pattern strength, Lost wax casting, Pattern tests, Sustainability, Recycling

\section{Introduction}

For the production of disposable patterns in the lost wax process usually special pattern materials are used, which are mixtures of defined composition determining their properties. Currently, they are produced by specialized companies. To add new wax pattern material into production in the precision foundry it is necessary to compare its properties with the properties of mixtures from recognized company. Accuracy of the patterns generated in the production phase depends mainly on:

1) wax patterns shape,

2) strength properties of pattern material,

3) shrinkage of the pattern material.
Strength properties of wax patterns are an essential element that has to be noted in the foundry. In the manufacturing process it is possible to carry out appropriate recycling of pattern materials. This causes reduction of production costs and it is based on adding the appropriate part of fresh mixture (new materials) to the mixture used before. In addition, it is necessary to check the properties of thus obtained pattern material. The main issues concern the study of mechanical properties, especially evaluation of bending strength (the most common method), evaluation of creep resistance, hardness evaluation and analysis of pattern material shrinkage in real patterns.

All of these tests should be carried out in relation to the ambient temperature in the foundry (patterns and ceramic molds the branch). Simultaneously, the injection pressure of pattern 
material in to form shaping patterns is determined, usually in the range between 0.5 to $3.0 \mathrm{MPa}$. The mentioned parameters influence the properties of the patterns and the possibility of using solid wax mixtures from companies such as Blayson or KindtCollins.

Evaluation of bending strength is problematic because of the need to use the right tools and specialized samples, although three-point bending test is often used $[1,2]$. Less complex tests are related to the evaluation of pattern material properties on the corresponding samples (or the actual wax patterns), which relates to the hardness and creep resistance. Hardness test is usually performed by penetration.

Assessment of pattern material creep in function of temperature is particularly useful for maintaining the appropriate complex shape and thin patterns. It is important to ensure minimum deformation, later influencing the accuracy of the casting [5].

\section{Research methodology of wax pattern properties study}

\subsection{Hardness of pattern material}

Figure 1 shows the measurement station used in the study. Hardness penetration method was based on the measurement of immersion in the studied of wax pattern compound needle of appropriate shape (Fig. 2) [3]. Load on measuring needle was 160 to 200 grams.

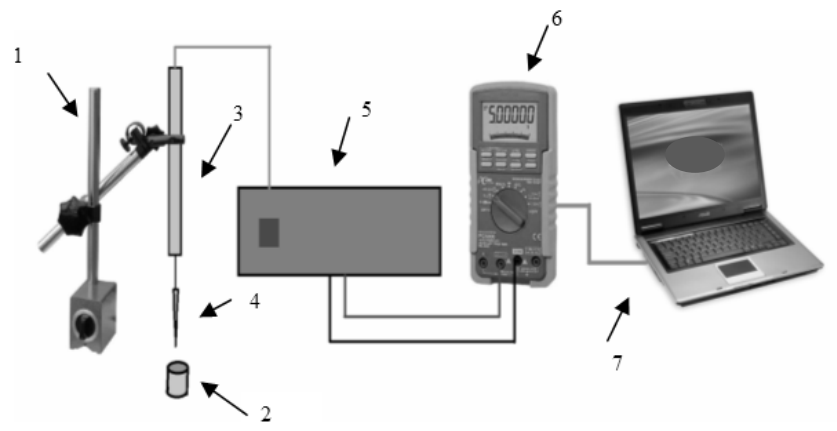

Fig. 1. Computer station for hardness testing using penetration method (1 - Holed for displacement sensor; 2 - Tested sample;

3 - Displacement sensor Ptx100; 4 - Penetration needle;

5 - Transducer, Amplifier; 6 - Multimeter Sanwa PC5000; 7 - Laptop with installed PC-link plus program)

Tested samples were cylindrical, their dimensions and the manufacturing method of industrial samples is shown in Table 1. In addition, small batch of cylindrical samples $\varnothing 26 \times 30 \mathrm{~mm}$ was made. Several samples from each pattern material were examined.

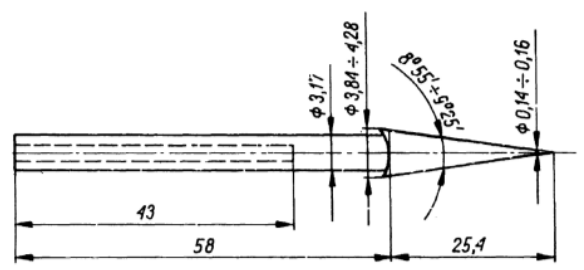

Fig. 2. Needle for hardness testing of wax patterns compounds

Table 1.

Conditions of cylindrical samples and industrial patterns hardness testing

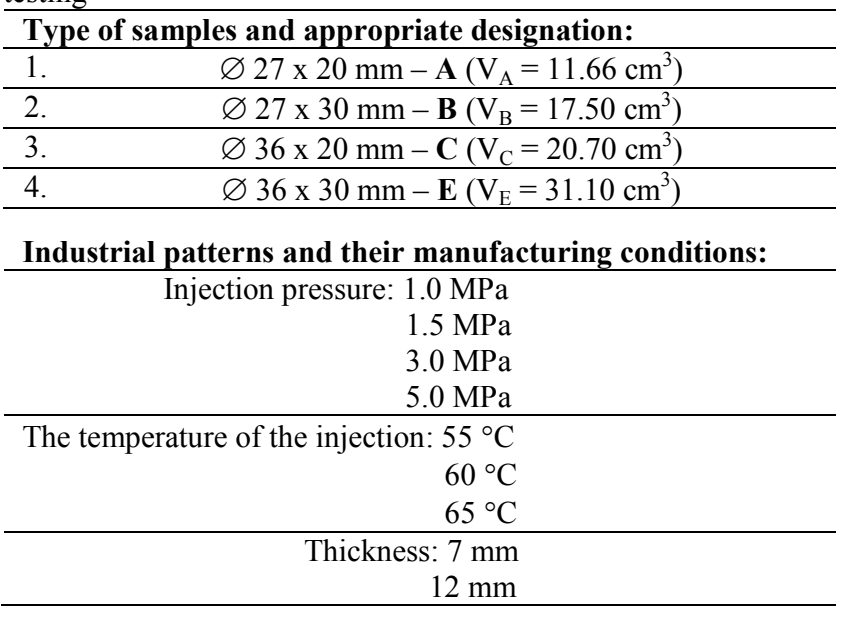

\subsection{Creep resistance}

The study was based on measuring the deflection curve of cylindrical samples with about $\varnothing 8 \mathrm{~mm}$ diameter which were deformed during 10 minutes as a result of 30 grams impact stress. Samples were placed so that the arm of impact load was located in $150 \mathrm{~mm}$. The base of research was deeply discussed in $[1,5]$. The device, on which tests were carried out are shown in Figure 3.

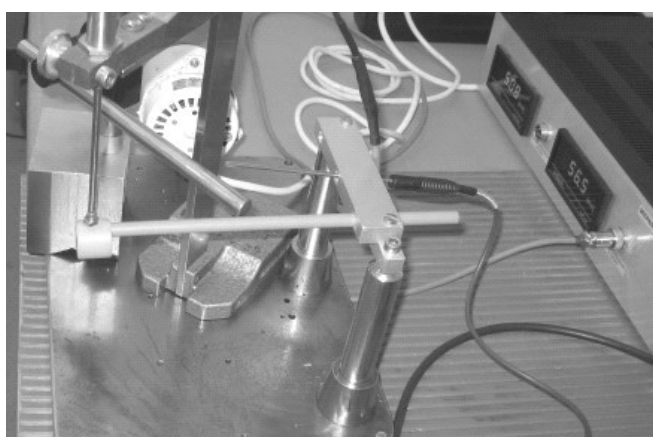

Fig. 3. The creep test station 
Measuring station consisted of a special mount to hold samples, inductive sensor with the extensions meter, and computer with measurement chart. The measurement time for each batch of samples (3 pieces) was 10 min. Several sets of measurements were made for the temperature 18 and $25^{\circ} \mathrm{C}$.

\section{The results}

\subsection{Evaluation of hardness with usage of penetration method}

A first series of tests was made for samples $\varnothing 26 \times 30 \mathrm{~mm}$ using a dial indicator to measure the movement of the penetration needle. The study was conducted on pattern material Blayson A7-FR60, Kindt-Collins KC4017 and blends of paraffin (P) and stearin (S) with additions of ceresin and polyethylene or Montana wax. In addition, a further series of tests at the position shown in figure 1 were made. In this case, several kinds of samples were made (Table 1) at different manufacturing pressures, obtained hardness was compared with the results obtained in the actual industrial wax patterns. All results are shown in Figure 4.

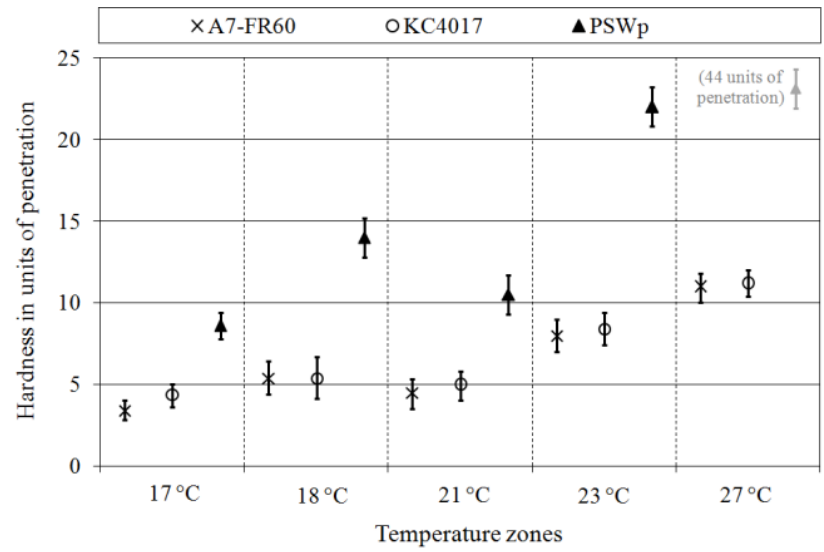

Fig. 4. The hardness of pattern material in different temperature zones

\subsection{Evaluation of resistance to creep}

Research findings made in the research station shown in Figure 3 are presented in Figure 5.

With the use of the same samples as used in the creep studies ( $\varnothing \mathrm{mm}$ ) bending strength was evaluated (three-point measurements) and the spacing of the supports was $50 \mathrm{~mm}$ the results were achieved and they are shown in Table 2.

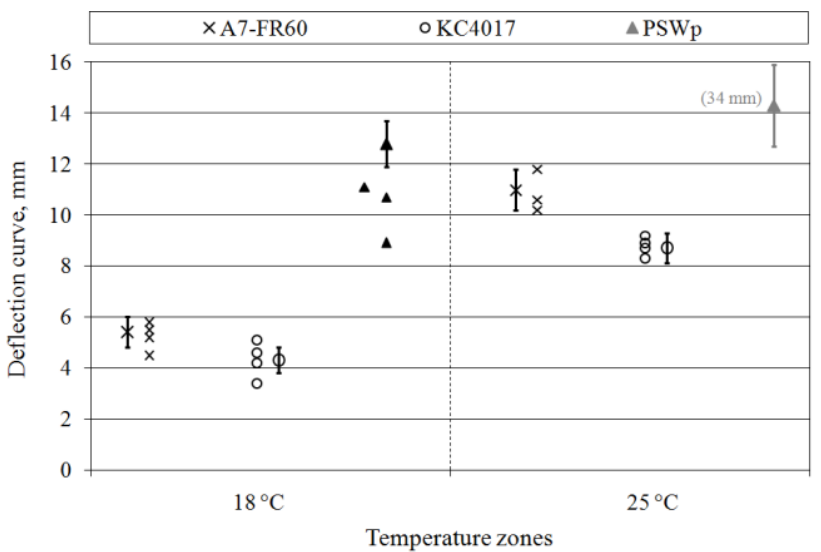

Fig. 5. The creep resistance of various pattern materials in the temperature zones 18 and 25 degrees $\mathrm{C}$

Table 2.

The results of $\varnothing 8 \mathrm{~mm}$ samples bending strength

\begin{tabular}{lc}
\hline $\begin{array}{l}\text { Type of pattern } \\
\text { material }\end{array}$ & $\begin{array}{c}\text { Average value of bending strength } \\
\mathrm{R}_{\mathrm{g}} \mathrm{avg}[\mathrm{MPa}]\end{array}$ \\
\cline { 2 - 2 } $\begin{array}{l}\text { Wax A7-FR60 } \\
\text { (Blayson) }\end{array}$ & $6.5_{-0.8}^{+0.7}$ \\
\hline $\begin{array}{l}\text { Wax KC4017 (Kindt } \\
\text { Collins) }\end{array}$ & $7.4 \pm 1.6$ \\
\hline $\begin{array}{l}\text { Mixture PSWp (3 } \\
\text { time used material } \\
\text { frol Polish foundry) }\end{array}$ & $3.2 \pm 0.4$ \\
\hline
\end{tabular}

\section{Summary of research results}

1) The sample size has little effect on the measured hardness value in units of penetration (for sample volume between $\mathrm{V}_{\mathrm{A}}=11.66 \mathrm{~cm}^{3}$ and $\mathrm{V}_{\mathrm{E}}=31.10 \mathrm{~cm}^{3}$ - see table 1$)$.

2) It is permissible to make hardness tests on actual real patterns, but the thickness of the pattern should be at least $12 \mathrm{~mm}$.

3) Measurement uncertainty while hardness $T_{w}$ tested for evaluated samples regardless of their size varied from approximately \pm 0.5 to \pm 1.3 units of penetration.

4) For the industrial wax patterns, when the thickness of the model was 12 or more than $12 \mathrm{~mm}$, the uncertainty was \pm 0.6 units of penetration (similar to the result of the smaller samples).

5) Significant influence of temperature on the pattern material properties was observed - hardness $T_{w}$ value and deflection curve during creep $f$ (Figs. 4 and 5).

6) Because of the fact that the hardness penetration is in inverse relation to the size of a conventional hardness results for metals, apparent hardness parameter was introduced in the wax patterns $T_{w p}=\frac{1}{T_{w}}$ and its value was in an average 0,196 for samples A7-FR60, 0,189 for $\mathrm{KC} 4017$ and 0,068 for a domestic pattern material (with 
paraffin). Therefore, in comparison with the results of bending $R_{g}$, the index $W=\frac{T_{w p}}{R_{g}}$ was obtained. Index $W$ is equal to:
a) for a pattern material A7-FR60 - $W=0.030$,
b) for a pattern material $\mathrm{KC} 4017-W=0.026$,
c) for a pattern material with paraffin and stearin - $W=0.021$.

7) Study of creep is strongly related to the ambient temperature, and it can be used in precision foundry for comparative evaluation of the analyzed pattern materials (especially in the case of slim patterns with thin walls) with other new pattern materials.

\section{Conclusions}

1) Apparent hardness of pattern material $T_{w p}$ (for penetration testing) should be less than the value of 0.15 .

2) Hardness of pattern material as compared to bending strength measured by the index $W$ is comparable for the test compound, and is ranging from 0.021 to 0.030 .

\section{References}

[1] Szklennik, L. \& Ozierow, V. (1994). Litje po wypławliajemym modieliam. Maszynostrojenije. Moskwa

[2] Belley, P.R., Smart, R.F. (1995). Investment Casting. Institute of materials. London

[3] Standard PN-EN 1426-2001.

[4] Arendarski, J. (2003). Measurement uncertainty. WUOT Publishing House. Warsaw,

[5] Collective work edited by Perzyk, M. (1995). Laboratory casting exercise book. WUOT Publishing House. Warsaw, 